\title{
SOS Games as an Alternative Game for Warming Up in Sports
}

\author{
Touvan Juni Samodra'), Uray Gus tian ${ }^{2)}$, Astiati $^{3}$ \\ Program studi Pedidikan Kepelatihan Olahraga \\ Fakultas Keguruan dan Ilmu Pendidikan \\ ${ }^{123}$ Universitas Tanjungpura, Indonesia \\ Email: ${ }^{1}$ tovan@ @ fkip.untan.ac.id, ${ }^{2} \underline{\text { uray.gustian@ @ fkip.untan.ac.id, }}, \underline{\text { astiati7666@ac.id }}$
}

\begin{abstract}
This study aimed to test the SOS game used as a means to warm up. SOS games were usually played on paper. The trial game consists of 3 different levels. This game could be used as a movement activity to warm up. With some modifications, this game was tested. The trial was conducted on junior high school students, totaling 40 students. The data was obtained by measuring the pulse. Pulse was measured by counting the pulse in the neck for 10 seconds. The calculation result is multiplied by 6 to determine the number of pulses per minute-data analysis by comparing the measurement results with heating criteria based on age. The results showed that the first trial had a pulse rate of 142. Based on trial with 40 samples each at level 1, 140 level 2, 143, and level 3, 143 beats per minute. All of these pulses were in the exercise pulse. So it can be recommended that this game be usedfor heating purposes.
\end{abstract}

\section{Keywords: SOS, Pulse, Sport, Warming Up}

\section{Permainan SOS Sebagai Alternative untuk Pemanasan dalam Olahraga}

\begin{abstract}
ABSTRAK
Tujuan penelitian ini untuk mengujicobakan permainan SOS untuk aktivitas pemanasan. Permainan SOS biasa dimainkan di atas kertas. Uji coba permainan terdiri dari 3 level yang berbeda. Permainan ini memiliki potensi untuk dijadikan aktivitas gerak sebagai permainan untuk pemanasan. Dengan beberapa modifikasi permainan ini diujicobakan. Uji coba dilakukan terhadap siswa sekolah menengah pertama, berjumlah 40 siswa. Data diperoleh dengan melakukan pengukuran denyut nadi. Nadi diukur dengan menghitung detak nadi di bagaian leher selama 10 detik. Hasil perhitungan dikalikan 6 untuk mengetahui jumlah nadi per menit. Analisis data dengan membandingkan hasil pengukuran dengan kriteria pemanas an berdasarkan umur. Hasil penelitian menunjukkan bahwa uji coba pertama rerata nadi 142 . Uji coba berikutnya dengan 40 sampel masing masing pada lavel 1, 140 level 2, 143 dan level 3, 143 denyut per menit. Semua denyut nadi tersebut ternyata sudah masuk dalam denyut nadi latihan. Sehingga dapat direkomendasikan permainan inidapat dipergunakan untuk kepentingan pemanasan.
\end{abstract}

Kata Kunci: SOS, denyut nadi, olahraga, Pemanasan

Info Artikel

Dikirim : 9 Oktober 2021

Diterima : 20 November 2021

Dipublikasikan : 30 November 2021
(C) 2021 IKIP BUDI UTOMO MALANG

P-ISSN 2613-9421

E-ISSN 2654-8003

\footnotetext{
\ Alamat korespondensi: tovan@fkip.untan.ac.id

Universitas Tanjungpura, Jl. Prof. Dr. H. Hadari Nawawi, Bansir Laut, Kec. Pontianak Tenggara, Kota Pontianak,

Kalimantan Barat 78124, Indonesia
} 


\section{PENDAHULUAN}

Pemanasan bisasanya dilakukan antara 10-20 menit dengan berjalan atau jogging competition (Chatel \& Williams, 2021). Pemanasan yang tidak cukup merupakan salah satu penyebab terjadinya cidera sampai 16,3\% (Gozali \& Kartiko, 2019; Supriyono, 2017). Atlet Taedkwonso Malaysia yang mengalami cidera pada umumnya adalah atlet yang belum professional. Sehinga proses latihan disarankan untuk lebih memberikan tekanan pada pemanasan dan stretching sebelum melakukan latihan inti dan setelah latihan inti (Jabbar et al., 2021). Selain itu (Fradkin, A. J., Gabbe, B. J., \& Cameron, 2006) mengatakan bahwa pemanasan efektif dapat mengurangi resiko cidera.

Sebuah penelitian memaparkan pengaruh pemanasan sebelum melakukan sprint dengan membagi dalam 2 kelompok. Kelompok pertama diberikan pemanasan berupa Static Stretching dan kelompok kedua Submaximal Running, ternyata hasilnya lebih bagus yang melakukan pe manasan Submaximal Running (Frota Solon \& da Silva Neto, 2021). Pesan dari hasil penelitian ini adalah, baha pemanasan sebaiknya dilakukan dengan aktivitas yang aktif dan dinamis. Aktivitas pasif juga merupakan hal yang penting, tetapi pemanasan dinamis lebih baik dalam menyiapkan tubuh untuk bekerja dengan intensitas yang tinggi. Penelitian lain menyebutkan bahwa pemanasan yang dilakukan secara rutin sebagai kebiasaan terhadap atlet bola basket sekolah menengah atas menunjukkan bahwa, pemanasan setidaknya dilakukan sampai 45 menit dengan berbagai jenis aktivitas, dengan dipandu oleh asisten pe latih yang terdiri dari akvitas kecil, game kecil. Kegiatan ini dilakukan sebagai upaya agar terhindar dari cidera (MunozPlaza et al., 2021)

Bukti penelitian menunjukkan (Bacharudin Yusuf, 2014) bahwa ada pengaruh signifikan dalam permainan terhadap efektifitas pembelajaraan jasmani yaitu sebesar $4 \%$. Hal yang sama juga dikatakan oleh (Finalosa, 2014), mengatakan bahwa pengaruh pemberian permainan kecil dalam pemanasan terhadap minat siswa yaitu sebesar $5,12 \%$. Pemanasan dengan menerapkan permainan dengan bola kecil ternyata dapat meningkatkan minat siswa untuk mengikuti pembelajaran penjas (Gustiawati, 2017; Kurnia \& Septiana, 2020). Dalam pembe lajaran gerak kata dalam karate agar menjadi lebih mudah di desain 
179 Touvan Juni Samodra ${ }^{1)}$, Uray Gustian ${ }^{2)}$, Astiati ${ }^{3}$.Jp.jok (Jurnal Pendidikan. Jasmani, Olahraga dan Kesehatan). 5(1) $177-188$

dengan senam (Ganda Hadi Wijaya et al., 2020). Pengembangan ini merupakan tindakan kreatif yang akan memberikan efek positif dalam pembelajaran. Pemanasan dengan ditambah vibrasi pada otot ternyata memberikan manfaat yang lebih baik sebagai persiapan untuk melakukan gerak yang eksplosif menendang dalam beladiri taekwondo (Chen et al., 2021). Meskipun dengan cara ini juga tidak memberikan dampak yang positif terhadap kelenturan.

Sebuah penelitian membandingkan antara pemanasan aktif, pasif serta gabungan antara kedua terhadap kinerja atlet, hasil menyarankan pemanasan lebih baik dilakukan kombinasi diantara ketiganya (McGawley et al., 2021). Lebih lanjut dinyatakan bahwa pemanasan dengan game ternyata dapat dipergunakan untuk pembelajaran dengan data peningkatan denyut nadi di nadi latihan yaitu 60\%-75\% dengan sampel siswa SMP (Suhendra et al., 2021). Bukti penelitian ini menguatkan bahwa pemanasan sangat penting. Ada hal yang perlu diperhatikan dalam pemanasan. Pertama peningkatan suhu dengan intensitas kerja 60\%-75\%, intensitas ini harapannya juga akan meningkat nadi di level yang sama. Pemanasan akan lebih baik jika dipilih dari aktivitas yang menyenangkan. Aktivitas yang menyenangkan seperti diungkapkan oleh (Gustiawati, 2017; Kurnia \& Septiana, 2020), harus dapat meningkatkan motivasi untuk mengikuti pembelajaran atau latihan.

Penelitian ini memilih permainan yang sudah dikenal secara kognisi, permainan ini sangat familier dilakukan dan menarik. Permainan SOS biasanya dimainkan di atas kertas dengan peraturan sederhana, siapa yang dapat membuat tulisan SOS secara berurutan tanpa putus dengan interval menyusun tulisan secara bergantian dan saling mematikan. Permainan di atas kertas tentunya lebih mudah. Dalam penelitian ini permainan dilakukan dengan desain di lapangan, dimainkan oleh dua tim yang berbeda dengan saling mematikan dan berusaha untuk membuat tulisan SOS pada ban yang telah disediakan. Terdapat beberapa hal yang menjadikan penelitian ini menarik, pertama kesenangan bergerak akan terjadi dengan berkompetisi, kedua aktivitas ini mudah dilaksanakan serta memiliki tantangan tersendiri untuk melaksanakan, ketiga hasil penelitian ini harapannya dapat dijadikan sebuah referensi baru tentang pengadopsian aktivitas pemanasan berdasarkan permamainan yang ada. Permainan yang ada direalisasikan dengan 
diujicobakan menjadi alternatif variasi pemanasan yang lebih menarik dibandingkan hanya lari keliling lapangan.

Berdasarkan kajian tentang pe manasan di atas, maka penelitian ini memilih salah satu permaianan yang di sebut "SOS". Permainan ini merupakan permainan saling mematikan langkah yang biasa dilakukan di atas kertas atau papan tulis. Siapa yang dapat menyusun kata "SOS" lebih cepat dengan giliran mejalankan permainan akan menjadi pemenang. Adapun video pelaksanaan permainan ini dapat diakses dalan link https://www.youtube.com/watch?v=5LJEpnFIhEY .

Uji coba ini dilakukan dengan memberikan beberapa modifikasi pada pelaksanaan SOS. Adapun modifikasi yang dilakukan bertujuan untuk lebih memberikan rintangan dan meningkatkan intensitas sebagai upaya menyiapkan fisiologi agar siap untuk me lakukan aktivita inti, serta meningkatkan rasa senang dalam partisipasi dalam olahraga. Penelitian ini harapannya dapat memberikan perbendaharan baru dalam melakukan pemanasan serta menyediakan contoh kecil dalam menyusunan pemanasan untuk kepentingan peningkatan kegiatan inti dalam olahraga. Olahrag yang dimaksud baik untuk tujuan pendidikan ataupun tujuan prestasi.

\section{METODE}

Penelitian dilakukan dengan one shot case study. Dilaksanakan tanggal 2025 Maret 2021. Orang coba adalah siswa Sekolah Menengah Pertama 40 siswa, 40 siswa ini gabungan antara kelas VIII D dan IX B SMP N 1 Selakau Timur di Kabupaten sambas, Kalimantan Barat. Rentang usia antara 13-15 tahun. Data diperoleh dengan melakukan pengukuran terhadap denyut nadi sesaat setelah melaksanakan game SOS, dengan menghitung jumlah denyut nadi dalam waktu 10 detik. Hasil hitungan kemudian dikalikan dengan 6, untuk mengetahui jumlah nadi per menit. Pengukuran denyut nadi dilakukan sebelum dan sesaat setelah selesai melakukan permainan. Penelitian ini juga memberikan pertanyaan singkat (7 butir pertanyaan) yang mencoba untuk meminta pendapat siswa setelah melakukan permainan SOS. Data denyut nadi kemudian dilihat hasilnya intensitas permanasan menurut Bompa dalam tabel 1 berikut: 
181 Touvan Juni Samodra ${ }^{1)}$, Uray Gustian ${ }^{2)}$, Astiati ${ }^{3}$.Jp.jok (Jurnal Pendidikan. Jasmani, Olahraga dan Kesehatan). 5(1) $177-188$

Tabel 1. Acuan denyut nadi latihan

\begin{tabular}{ccc}
\hline Zona latihan & Batas & Status \\
\hline Daya tahan level 1 & $<75 \%$ & Nadi recovery \\
Daya tahan level 2 & $75-85 \%$ & Masih terasa nyaman \\
Daya tahan level 3 & $85-92 \%$ & Terasa tidak nyaman \\
Daya tahan level 4 & $>92 \%$ & Stress \\
\hline
\end{tabular}

Sumber (Tudor O. Bompa, 2019)

Data dianalisis dengan deskriptif statistic dan melakukan pengecekan kaitan dengan denyut nadi latihan sesuai dengan umur. Data di analisis dengan menggunakan bantuan software Exel. Berikut adalah tabel level dalam permainan SOS.

Tabel 2. Peraturan Pelaksanaan Permainan

\begin{tabular}{ll}
\hline Peraturan & SOS yang dimainkan terdiri dari 16 kotak (4x4) \\
umum & Permainan dilakukan kompetisi antara dua kelompok \\
& Setiap kelompok memiliki satu macam warna pada kertas \\
& Kelompok pe menang adalah kelompok yang terlebih dahulu \\
& menciptakan SOS secara segaris baik itu horizontal, vertical ataupun \\
& diagonal. \\
\hline Level 1 & Setiap kelompok terdiri dari 4 orang \\
& Dengan aba aba siap Yaa. Antar ke lompok berusaha meletakkan \\
& kartas berwarna membentuk tulisan SOS secara estafet. \\
Kelompok paling cepat menyusun SOS keluar sebagai pemenang & \\
& Pelaksanaan permainan sama dengan level 1, ditambah adanya kata \\
& kunci (kelinci) ketika guru menyebutkan kata kunci maka cara \\
& pemain menuju tempat penyusunan SOS dilakukan dengan \\
& melompat cone yang telah disediakan. \\
& Kelompok paling cepat menyusun SOS keluar sebagai pemenang \\
Terdapat penambahan aktivitas berdasarkan kata kunci yang \\
Level 3 3 diberikan. Kelinci (melompat) siput (bergerak sesuai kesepakan \\
dalam kelompok) dan kancil (sprint) \\
Kata kunci ini merupakan instruksi bagaimana pemain akan \\
bergerak \\
Kelompok paling cepat menyusun SOS keluar sebagai pemenang \\
\hline
\end{tabular}

\section{HASIL DAN PEMBAHASAN}

\section{HASIL}

Berdasarkan pengukuran yang dilakukan terhadap denyut nadi yang telah dilakukan terhadap permainan SOS dengan tiga level yang berbe da diperoleh 3 data denyut nadi dari 40 siswa. Tabel 1 memberikan gambaran bahwa nilai rerata denyut nadi sebelum melakukan pemanasan berkisar dari 79-81 per menit. Setelah 
melakukan permainan SOS dari level 1-3 secara berurutan capaian denyut nadi adalah 140, 143 dan 143 denyut rerata per menit. Data dari pengukuran denyut nadi untuk permainan SOS level 1 adalah sebagai berikut:

Tabel 3. Hasil Uji Coba Pengukuran Denyut Nadi Sebelum dan Sesaat setelah Bermain SOS Level 1-3

\begin{tabular}{lcccccc}
\hline & \multicolumn{3}{c}{ Denyut Nadi Sebelum Game } & \multicolumn{3}{c}{ Denyut Nadi Sesaat Setelah Game } \\
& \multicolumn{3}{c}{ Sos } & & & \multicolumn{3}{c}{ Sos } \\
\hline & 1 & 2 & 3 & 1 & 2 & 3 \\
Mean & 81 & 80 & 79 & 140 & 143 & 143 \\
Median & 78 & 81 & 78 & 144 & 144 & 144 \\
Modus & 78 & 78 & 78 & 144 & 144 & 144 \\
Standar & 5.5 & 6.2 & 6.4 & 4.2 & 54 & 3.4 \\
deviasi & 72 & 72 & 66 & 132 & 132 & 132 \\
Minimal & 90 & 90 & 90 & 144 & 156 & 156 \\
Maksimal & 90 & & & & &
\end{tabular}

Pada gambar 1 berikut secara nyata dapat dilihat bahwa capaian denyut nadi dari permainan ini ternyata telah mencapai nadi mendekati 150 , dan rerata terletak pada 140 per menit. Capaian denyut nadi ini mengindikasikan bahwa permainan dapat meningkatkan denyut nadi sampai level pemanasan. Adapun tampilan perbandingan nadi dari ringkasan setiap level disajikan dalam tabel sebagai berikut:

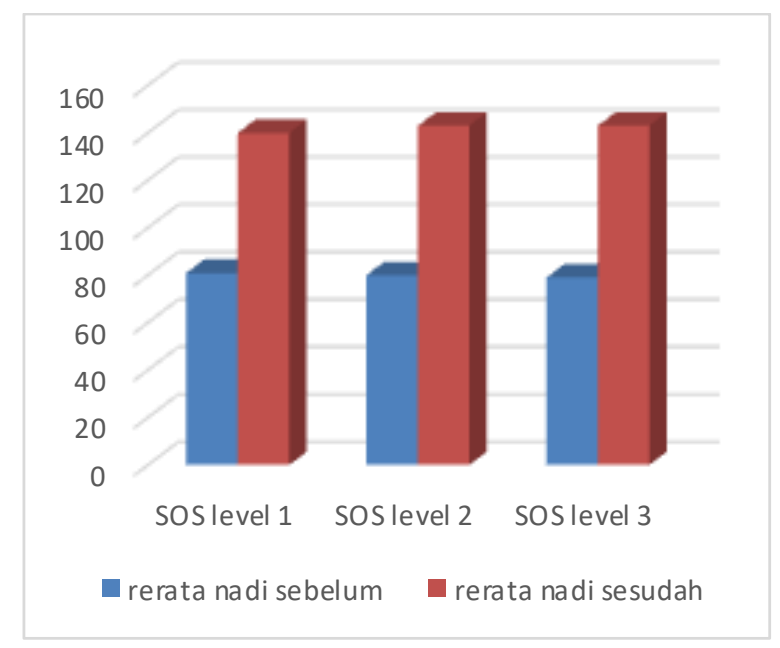

Gambar 1. Perbandingan Capaian Nadi Permainan SOS Dari Ketiga Level 
183 Touvan Juni Samodra ${ }^{1)}$, Uray Gustian ${ }^{2)}$, Astiati ${ }^{3}$.Jp.jok (Jurnal Pendidikan. Jasmani, Olahraga dan Kesehatan). 5(1) $177-188$

Hasil penelitian berikutnya kaitan dengan hasil jawaban terhadap angket yang telah disusun. Kaitan dengan tanggapan siswa terhadap pemanasan SOS yang telah dilakukan, dengan hasil sebagai berikut:

Tabel 4. Data kuisoner setelah di berikan permainan

\begin{tabular}{lllc}
\hline \multirow{2}{*}{ No } & \multicolumn{1}{c}{ Pertanyaan } & \multicolumn{2}{c}{ Prsentase } \\
& \multicolumn{1}{c}{ Ya } & Tidak \\
\hline 1 & Apakah permainan ini menyenangkan ? & 100 & 0 \\
2 & Apakah permainan ini membosankan ? & 0 & 100 \\
3 & Apakah permainan ini mengasikan ? & 100 & 0 \\
4 & Apakah permainan ini mudah untuk di pahami ? & 100 & 0 \\
5 & Apakah permainan ini mudah untuk di lakukan ? & 100 & 0 \\
6 & Apakah permainan ini bisa meningkatkan semangat & 100 & 0 \\
7 & untuk & \multirow{2}{*}{100} & 0 \\
& Apakah pemanasan dengan permainan ini lebih & & \\
\hline
\end{tabular}

Jawaban dari 7 pertanyaan yang disusun me mberikan informasi kesenangan dalam melakukan permainan SOS yang telah dilakukan. Berdasarkan tabel di atas dapat disimpulkan bahwa permainan ini manarik, menyenangkan, mudah dilakukan dan tidak membosankan.

\section{PEMBAHASAN}

Bahwa denyut nadi latihan untuk olahraga adalah berkisar antara 120 sampai 150 denyut nadi (tabel 1). Berdasarkan pada tabel 1, denyut nadi latihan berada minimal pada level 1, yaitu sampai $75 \%$. Dalam penelitian ini usia siswa berkisar antara 13-15 tahun. Dengan nadi maksimal adalah 220-umur maka rentang denyut nadi minimal agar masuk denyut nadi latihan disajikan dalam gambar 2 berikut: 


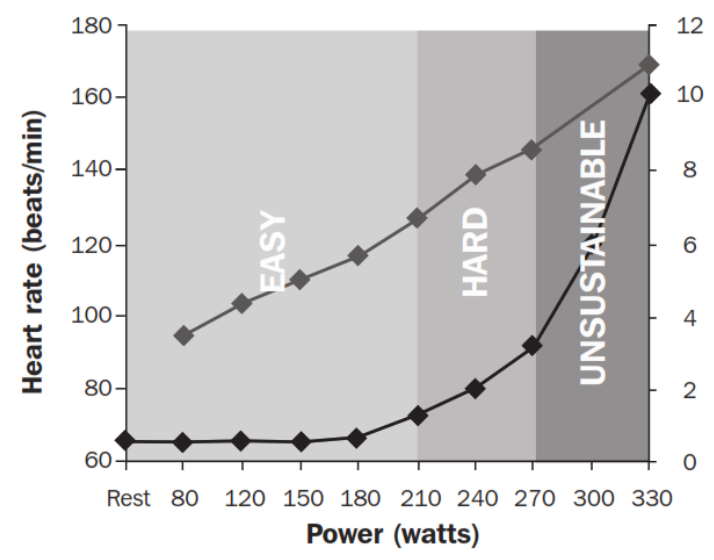

Gambar 2. Daerah pengelompokan denyut nadi latihan Sumber (Denis, 2008)

Berdasarkan tabel di atas, dapat dilihat bahwa, capaian denyut nadi latihan jelas sesuai sebagai capaian denyut nadi pemanasan. Hal ini menunjukkan bahwa permainan SOS dengan ketiga level di atas dapat dipergunakan sebagai pemanasan. Aktivitas ini lebih menyenangkan dan lebih dapat meningkatkan motivasi untuk melaksanakan olahraga berdasarkan tabel 4, dengan latihan memiliki pengaruh terhadap rasa senang (Gradari et al., 2016). Kajian pemanasan ini sangat penting. Mengingat kualitas kinerja otot dan kesiapan psikologi dipengaruhi oleh kegiatan pe manasan sebelum masuk ke olahraga inti. Penamasan berupa aktivitas lari, penguatan, pliometerik, keseimbangan dan kelincahan ternyata efektif untuk meningkat kinerja atlet (Chatel \& Williams, 2021).

Penelitian terdahulu memberikan gambaran bahwa, pemanasan dengan permainan ternyata efektif untuk dipergunakan (Yusuf \& Hartati, 2014). Telah dilakukan upaya pengembangan pemanasan yang dinamis sebagai media pembelajaran dalam pendidikan jasamani (Johandi Yusuf et al., 2020). Bahkan untuk tuna netra pemanasan dapat dilakukan dengan berbasis gerak dan lagu (Kusworo \& Winarni, 2017). Lebih lanjut, modifikasi yang dilakukan terhadap permainan tradisional juga dapat dipergunakan untuk pemanasan, dan terbukti dapat meningkatkan kelenturan siswa (Abdul Latif Rusdi, 2018). Olahraga tradisional berupa permainan dapat disisipkan dan dilaksanakan dalam penamasan sebelum masuk dalam materi inti (Permana et al., 2018). Penelitian ini memberikan dukungan untuk lebih kreatif dalam pemanasan dan memberikan alternatif aktivitas bermain agar nuansa senang dapat berlanjut sampai pada inti pembe lajaran. Demikian juga dengan pemberian permainan untuk pemanasan, hal 
185 Touvan Juni Samodra ${ }^{1)}$, Uray Gustian ${ }^{2)}$, Astiati ${ }^{3}$.Jp.jok (Jurnal Pendidikan. Jasmani, Olahraga dan Kesehatan). 5(1) $177-188$

ini terbukti memberikan dampak yang berbeda jika dibandingkan dengan kolompok yang tidak diberikan permainan (Lusianti, 2015). Dengan pemberian pemanasan permainan tentu saja memberikan rangsangan yang positif terhadap siswa kaitan dengan keikutsertaan dalam pembelajaran pendidikan jasmani. Kajian-kajian ini semakin menguatkan bahwa, pemanasan merupakan bagaian awal yang sangat penting sebelum melaksanakan aktivitas olahraga yang lebih berat. Pemanasan yang biasa dilakukan dengan keliling lapangan merupakan pemanasan dimanis, pada kenyataannya pemanasan ini lebih banyak dilakukan oleh guru pendidikan jasmani (I Andi, YTJ Samodra, 2021), akan tetapi pemanasasan dengan cara ini secara nyata mengurangi minat untuk bergerak. Pemanasan dalam bentuk permainan lebih dianjurkan agar aktivitas olahraga sedari awal memiliki nilai menyenangkan dan akan menimbulkan motivasi tersendiri untuk melanjutkan ke aktivitas yang lebih tinggi.

Berdasarkan kajian penelitian relevan memberikan dukungan bahwa pemanasan ini setidaknya memiliki beberapa sumbangan secara keilmuan dan praktis. Pertama pemanasan modifikasi SOS menimbulkan kesenangan, kedua secara intensitas dapat dipergunakan sebagai aktivitas untuk pemanasan, ketiga dapat memberikan contoh hal kecil baru tentang pelaksanaan pemanasan, keempat pemahasan ini mudah dilakukan dengan ketersedian bahan yang mudah ditemukan. Secara keilmuan telah dibuktikan bahwa nadi latihan terbukti tercapai dengan aktivitas yang dilakukan.

Titik penting dalam penelitian ini merupakan hasil uji coba pemanasan yang dilakukan dengan permainan SOS. Salah satu tolok ukur keberhasilan dalam pemanasan adalah telah siapnya tubuh yang diidentifikasi dengan denyut nadi. Pemanasan yang dilakukan secara konvensional (lari keliling lapangan) (I Andi, YTJ Samodra, 2021), dinyatakan terlalu umum untuk dilakukan. Sehingga hasil penelitian ini memberikan kreasi baru. Berdasarkan pengecekan terhadap denyut nadi permainan SOS ini dapat dipergunakan, bukti kedua, dari 7 butir pertanyaan yang disampaikan ke siswa dapat ditarik kesimpulan bahwa permainan ini menarik, lebih menyenangkan dibandingkan dengan jogging (tabel 4). 


\section{SIMPULAN}

Hasil penelitian ini me mbuktikan bahwa perma inan SOS dengan pembagian level 1, 2 dan 3, berdasarkan bukti lapangan yang diujikan terhadap siswa SMP membuktikan dapat dipergunakan untuk melakukan pemanasan. Bukti berikutnya permainan ini menarik, mudah, dan menyenangkan. Hal ini ditunjukkan dengan capaian nadi yang mencapai nadi latihan dan hasil angket.

\section{DAFTAR RUJUKAN}

Abdul Latif Rusdi. (2018). Permainan tradisional sebagai alternatif pemanasan olahraga sekaligus peningkatan fleksibilitas siswa. Permainan Tradisional Sebagai Alternatif Pemanasan Olahraga Sekaligus Peningkatan Fleksibilitas Siswa. http://digilib.unimed.ac.id/id/eprint/35708

Bacharudin Yusuf, W. (2014). Pengaruh Pemanasan Dalam Bentuk Permainan Terhadap Efektivitas Pembelajaran Pendidikan Jasmani, Olahraga Dan Kesehatan (Studi Pada Siswa Kelas X Smkn 1 Dlanggu Mojokerto). Jurnal Pendidikan Olahraga Dan Kesehatan, 2(1), 64-66.

Chatel, M. M., \& Williams, J. M. (2021). What's in a warm-up? A preliminary investigation of how European dressage riders and show jumpers warm-up their horses for training and at competition. Comparative Exercise Physiology, 17(2). https://doi.org/10.3920/CEP200035

Chen, A. H., Chiu, C. H., Hsu, C. H., Wang, I. L., Chou, K. M., Tsai, Y. S., Lin, Y. F., \& Chen, C. H. (2021). Acute effects of vibration foam rolling warm-up on jump and flexibility asymmetry, agility and frequency speed of kick test performance in taekwondo athletes. Symmetry, 13(9). https://doi.org/10.3390/sym13091664

Denis, G. O. and R. (2008). Heart Rate Training (S. Bordiss (ed.)). P2P Publishing Ltd.

Finalosa, F. (2014). Pengaruh Pemberian Permainan Kecil Dalam Pemanasan Terhadap Minat Siswa Dalam Pembelajaran Bolabasket (Studi Pada Siswa Kelas Viii Smp Negeri 2 Babadan, Ponorogo). Jurnal Pendidikan Olahraga Dan Kesehatan, 2(3).

Fradkin, A. J., Gabbe, B. J., \& Cameron, P. A. (2006). Does Warming Up Prevent Injury In Sport?. The Evidence From Randomised Controlled Trials? Journal Of Science And Medicine In Sport. https://doi.org/Https ://Doi.Org/10.1016/J.Jsams.2006.03.026

Frota Solon, L. J., \& da Silva Neto, L. V. (2021). Effect of Static Stretching and 
187 Touvan Juni Samodra ${ }^{1)}$, Uray Gustian ${ }^{2)}$, Astiati ${ }^{3}$.Jp.jok (Jurnal Pendidikan. Jasmani, Olahraga dan Kesehatan). 5(1) $177-188$

Submaximal Running on Contramovement Jump Performance and Sprint on College Volleyball Players. $\quad 39$. https://doi.org/10.47197/retos. v0i39.79344

Ganda Hadi Wijaya, Muhammad Muhyi, \& Yoso Wiyarno. (2020). Pengembangan Model Pembelajaran Senam Karate Kids (Skk) Di Sdi At'taqwa Surabaya. Jurnal Kejaora (Kesehatan Jasmani Dan Olah Raga), 5(1), 6-13. https://doi.org/10.36526/keja ora.v5i1.760

Gozali, I., \& Kartiko, D. C. (2019). Survei Tingkat Pengetahuan Guru Pjok Tentang Pertolongan. Jurnal Pendidikan Olahraga Dan Kesehatan, 9(1), $179-182$.

Gradari, S., Pallé, A., Mc Greevy, K. R., Fontán-Lozano, Á., \& Trejo, J. L. (2016). Can exercise make you smarter, happier, and have more neurons? A hormetic perspective. Frontiers in Neuroscience, 10(MAR). https://doi.org/10.3389/fnins.2016.00093

Gustiawati, R. (2017). Penerapan Materi Model Pembelajaran Permainan Kecil Di Dalam Pemanasan Terhadap Motivasi Belajar Pendidikan Jasmani Olahraga Dan Kesehatan Pada Siswa Kelas Vi Sdn Mekarsari 05 Tambun Selatan Kabupaten Bekasi. Motion: Jurnal Riset Physical Education, 8(1), 50-58.

I Andi, YTJ Samodra, U. G. (2021). Identifikasi kebiasaan pemanasan pada mata pelajaran pendidikan jasmani di sekolah. Edu Sportivo, 2(3), 164-170. https://doi.org/https ://doi.org/10.25299/es :ijope.2021.vol2(3).7504

Jabbar, M. A., Chandran, J., Yuan, O. Y., \& Masilamani, R. (2021). Prevalence of musculoskeletal injuries among taekwondo players in Malaysia. Malaysian Journal of Public Health Medicine, 21(2). https://doi.org/10.37268/mjphm/vol.21/no.2/art.1072

Johandi Yusuf, Muhammad Muhyi, \& Yoso Wiyarno. (2020). Pengembangan Pemanasan Dinamis Dalam Pembelajaran Pendidikan Jasmani Olahraga Dan Kesehatan (Pjok) Tingkat Sekolah Menengah Pertama. Jurnal Kejaora (Kesehatan Jasmani Dan Olah Raga), 5(1), 79-85. https://doi.org/10.36526/keja ora.v5i1.762

Kurnia, D., \& Septiana, R. A. (2020). Implementasi Permainan Kecil Sebagai Bentuk Pemanasan Terhadap Minat Siswa dalam Pembelajaran Pendidikan Jasamani. Physical Activity Journal, 2(1), Journal (PAJU), [S.1.], v. 2, n. 1, pages 90-99. https://doi.org/10.20884/1.paju.2020.2.1.3302

Kusworo, H., \& Winarni, S. (2017). Model pemanasan berbasis gerak dan lagu bagi anak tunanetra. Jurnal Pendidikan Jasmani Indonesia, 13(1), 19-24. https://doi.org/10.21831/jpji.v13i1.21024

Lusianti, S. (2015). Pengaruh Pemberian Permainan Sebagai Bentuk Pemanasan 
Terhadap Minat Siswa Dalam Mengikuti Pelajaran Pendidikan Jasmani. Jurnal SPORTIF: Jurnal Penelitian Pembelajaran, 1(1), 32-34. https://doi.org/10.29407/js_unpgri.v1i1.573

McGawley, K., Spencer, M., Olofsson, A., \& Andersson, E. P. (2021). Comparing active, passive, and combined warm-ups among junior alpine skiers in $-7^{\circ} \mathrm{C}$. International Journal of Sports Physiology and Performance, 16(8). https://doi.org/10.1123/IJSPP.2020-0300

Munoz-Plaza, C., Pounds, D., Davis, A., Park, S., Sallis, R., Romero, M. G., \& Sharp, A. L. (2021). High School Basketball Coach and Player Perspectives on Warm-Up Routines and Lower Extremity Injuries. Sports Medicine Open, 7(1). https://doi.org/10.1186/s40798-021-00328-4

Permana, R., Nugraha, M. F., Hendrawan, B., Pratiwi, A. S., Nurfitriani, M., \& Saleh, Y. T. (2018). Sosialisasi olahraga tradisional untuk meningkatkan kebugaran dan minat siswa sd terhadap pembelajaran olahraga di wilayah kecamatan tamansari. ABDIMAS: Jurnal Pengabdian Masyarakat, 1(1), 1-6. https://doi.org/10.35568/abdimas.v1i1.233

Suhendra, A. F., Samodra, Y. T. J., \& Gustian, U. (2021). Pengembangan Pemanasan Dengan Game Bagi Siswa SMP. Journal RESPECS, 3(2). https://doi.org/10.31949/respecs.v3i2.1037

Supriyono, S. (2017). Analis is cedera olahraga dalam aktivitas pendidikan jasmani pada siswa sma negeri 1 nalumsari. E-Jurnal Physical Education, 6(1), 45-52. https://doi.org/10.15294/active.v6i1.13255

Tudor O. Bompa, G. G. H. (2019). Periodization: Theory and Methodology of Training, 6th Edition. Medicine \& Science in Sports \& Exercise. https://doi.org/10.1249/01.mss.0000554581.71065.23

Yusuf, W. B., \& Hartati, S. C. Y. (2014). Pengaruh Pemanasan Dalam Bentuk Permainan Terhadap Efektivitas Pembelajaran Pendidikan Jasmani, Olahraga dan Kesehatan. Jurnal Pendidikan Olahraga Dan Kesehatan. 